\title{
Pengaruh Pengawasan Terhadap Disiplin Kerja Pegawai Negeri Sipil Pada Sekretariat DPRD Provinsi Sulawesi Tenggara
}

\author{
Asmita ${ }^{1} ;$ Rahman $^{2} ;$ Nasir $^{3}$ \\ ${ }^{123}$ Universitas Halu Oleo, asmitaseptianigani96@gmail.com
}

\begin{abstract}
Abstrak
Penelitian ini bertujuan untuk mengetahui pengaruh pengawasan terhadap disiplin kerja pegawai negeri sipil pada sekretariat DPRD Provinsi Sulawesi Tenggara. Populasi penelitian ini adalah seluruh pegawai negeri sipil pada sekretariat DPRD Provinsi Sulawesi Tenggara berjumlah 210 orang. Sampel dalam penelitian ini adalah 53 responden. Metode pengumpulan data melalui kuesioner. Teknik analisis data yang digunakan adalah regresi linier sederhana dengan bantuan SPSS 24 for windows. Hasil penelitian ini menunjukkan bahwa Pengawasan berpengaruh positif dan tidak signifikan terhadap disiplin kerja pegawai negeri sipil pada sekretariat DPRD Provinsi Sulawesi Tenggara.
\end{abstract}

Kata kunci : Inovasi, Pelayanan, Publik, Strategi,.

\begin{abstract}
This research aims to know the influences of supervisory work discipline against civil servants in the provincial secretariat of Southeast Sulawesi. The population of this research is the entire civil servant in the provincial secretariat Indonesia amounted to 210 people. The sample in this research were 53 respondents. Method of collecting data through questionnaires. Data analysis technique used was simple linear regression with the help of SPSS for windows 24. The results of this research show that the positive effect of supervision and not significantly to discipline civil servants working at the Secretariat of the local parliament of the province of South East Sulawesi.
\end{abstract}

Keywords : Innovation, Service, Public, Strategic.

\section{Pendahuluan}

Peranan sumber daya manusia merupakan salah satu faktor utama yang sangat penting dalam suatu organisasi. Pemanfaatan sumber daya manusia secara efektif merupakan jalan bagi suatu organisasi untuk mempertahankan kelangsungan hidup dan pertumbuhan dimasa yang Akan datang. Dengan kata lain, keberhasilan atau kemunduran suatu organisasi tergantung pada keahlian dan keterampilan pegawainya masing-masing yang bekerja didalamnya.Pegawai Negeri Sipil merupakan sumber daya manusia aparatur negara yang bertugas memberikan pelayanan kepada masyarakat secara profesional, jujur, adil dan merata dalam penyeleggaraan tugas negara, pemerinahan dan pembangunan, dengan dilandasi kesetiaan, dan ketaatan kepada pancasila dan Undang-Undang 1945. 
Berdasarkan Undang-Undang Nomor 5 tahun 2014 tentang Aparatur Sipil Negara,bahwa untuk mewujudkan aparatur sipil Negara sebagai bagian dari reformasi birokrasi, perlu di tetapkan aparatur Negara sipil sebagai profesi yang memiliki kewajiban mengelola dan mengembangkan dirinya dan wajib mempertanggung jawabkan kinerjanya dengan menerapkan prinsip merit dalam pelaksanaan manajemen aparatur sipil Negara.Citra birokrasi pemerintahan secara keseluruhan akan banyak di tentukan oleh kinerja organisasi tersebut. Pegawai Negri Sipil jarang mendapatkan pendidikan dan pelatihan secara rutin. Tidak jarang yang sudah bekerja lebih dari 8 tahun, pendidikan yang di dapat baru pra jabatan,yang memang wajib bagi calon Pegawai Negeri Sipil akan di angkat menjadi Pegawai Negeri Sipil. Kedudukan dan peranan Pegawai Negeri Sipil di Indonesia dirasakan semakin penting untuk menyelenggarakan pemerintahan dan pembangunan dalam usaha mencapai tujuan nasional yaitu mewujudkan masyarakat yang madani yang taat akan hukum, berperadapan modern, demokratis, makmur, adil dan bermoral tinggi.

Kedudukan dan peranannya yang penting menyebabkan Pegawai Negeri Sipil senantiasa dituntut supaya memiliki kesetiaan dan ketaata penuh dalam menjalankan tugas-tugasnya dan memusatkan seluruh perhatian serta megarahkan segala daya dan tenaga. Pada prinsipnya pemberian tugas kedinasan itu adalah merupakan kepercayaan dari atasan yang berwenang dengan harapan bahwa tugas ituakan di laksanakan dengan sebaik-baiknya, dengan demikian maka setiap pegawai negeri wajib melaksanakan tugas kedinasan yang telah di percayakan kepadanya dengan penuh pengabdian, kesadaran, dan tanggung jawab. Menurut Sujamto (2011:17) menyatakan pengawasan adalah untuk menentukan apa yang telah dicapai,mengadakan evaluasi atasannya,dan mengambil tindakan-tindakan korektif bila di perlukan untuk menjamin agar hasilnya sesuai dengan rencana.

Pengawasan yang baik diharapkan akan mengurangi kesalahan dan penyimpangan yang terjadi. Selain itu, menurut Siagian (2002:112) pengawasan adalah proses pengamatan dari pelaksanaan seluruh organisasiuntuk menjamin agar semua pekerjaan yang sedang dilaksanakan berjalan sesuaidengan rencana yang telah ditetapkan sebelumnya. 
Berdasarkan penjelasan diatas dapat disimpulkan bahwa pengawasan adalah kewajiban setiap atasan untuk mengatasi setiap bawahannya yang bersifat prefentif dan pembinaan,untuk menciptakan aparatur yang lebih efektif,efesien,bersih dan beribawa terutama dalam menanggulangi masalah korupsi, penyelagunaan wewenang, kebocoran dan pemborosan keuangan negara. Pengaruh pengawasan terhadap disiplin kerja pegawai menjadi sangat penting untuk di bahas. Hal ini di maksud untuk melihat apakah dengan di adakannya pengawasan dapat berpengaruh terhadap disiplin kerja pegawai pada suatu instansi di Sekretariat DPRD Provinsi Sulawesi Tenggara. Pada instansi pemerintahan yang perludilakukan pengawasan yang efektif sehingga disiplin atau etos kerja pegawai dapat di tingkatkan untuk memacu produktifitas kerja pegawai yang tinggi. Apabila ada pengawasan yang dilakukan secara efektif dari manajer maka semangat kerja akan timbul,dan para pegawai secara otomatis akan bekerja rajin dengan disiplin kerja yang tinggi serta bertanggung jawab sehingga produktifitas kerja dapat meningkat dengan sendirinya.

Pengawasan ini dilakukan oleh manajer sebagai suatuusaha membandingkan apakah yang dilakukan sesuai dengan rencana yang ditetapkan.Hal ini berarti juga pengawasan merupakan tindakan atau kegiatan manajer yang mengusahakan agar pekerjaan terlaksana sesuai dengan rencana yang ditetapkan atau hasil kerja yang dikehendaki. Semakin lancar kerja dan disertai pengawasan yang baik maka akan mendorong pengawai lebih giat dalam bekerja dan menghasilkan kerja yang baik pula terlebih apabila menyelesaikan pekerjaan dengan semangat yang baik.

Pengawasan pada dasarnya merupakan aktivitas membandingkan kondisi yang ada dengan kondisi yang seharusnya terjadi.Bila ternyata ditemukan adanya penyimpangan atau hambatan segera diambil tindakan koreksi .Agar dapat efektif mencapai tujuannya,pengawsan tidak dilakukan hanya pada saat akhir proses manajemen saja,akan tetapi berada pada setiap tingkatan proses manajemen .Dengan demikian pengawasan akan memberikian nilai tambah bagi peningkatan pelayanan atau kinerja organisasi. 
Secara ringkas dapat dikatakan bahwa pengawasan adalah proses untuk menjamin agar tujuan organisasi dan manajemen tercapai.Dengan demikian tujuan dan urgensi pengawsan meliputi: 1). Untuk mengetahui apakah hasil kegiatan yang dilakukan telah sesuai dengan rencana yang telah ditetapkan. 2). Apakah pelaksanaan visi, misi, sesuai dengan kebijaksanaan, pengarahan, prosedur dan pedoman-pedoman yang telah ditetapkan. 3). Untuk mengetahui apakah ada kesulitan-kesulitan hambatan-hambatan, tantangan, peluang dan potensi-potensi yang penting diketahui untuk keberhasilan pencapaian tujuan dan bilamana perlu melaksanakan tindakan koreksi. 4). Apakah pelaksanaan kegiatan tersebut dapat berjalan secara efisien, efektif, dan produktif dilihat dari tenaga, biaya, perlengkapan/peralatan dan sarana prasarana yang ada.

Berdasarkan uraian di atas,dapat diketahui bahwa salah satu urgensi dan tujuan pengawasan adalah untuk mencengah terjadinya penyimpangan dan penyelewengan dari aturan dan perundang-undangan yang berlaku dalam pelaksanaan tugas dan fungsi manajemen. Dengan melakukan pengawasan yang baik atau efektif, maka diharapkan para Pengawai Negeri Sipil tidak melakukan pelanggaran disiplin atau dengan kata lain dapat mendorong pengawai untuk meningkatkan disiplin kerja mereka.

Pengawai negeri sipil pada Sekretariat DPRD Provinsi Sulawesi Tenggara sebagai salah satu birokrasi publik ditingkat Provinsi menjalankan fungsi pelayanan kepada masyarakat, sesuai hasil pengamatan awal memperlihatkan kecenderungan belum optimalnya penerapan peraturan disiplin kerja pengawai, terutama berkaitan dengan disiplin dalam menggunakan waktu kerja. Kondisi ini diindikasikan dengan perilaku sebagian pengawai yang cenderung mengabaikan pemanfaatan waktu kerja yang lebih efektif dan efisien.

Salah satu contoh klasik adalah bahwa sebagian pengawai sering datang dan pulang kerja kurang tepat waktu serta melakukan kegiatan lain pada saat jam kerja, Seperti menjemput anak sekolah, berjalan-jalan/makan siang diluar kantor,terutama dipusat perbelanjaan dan lain-lain. Fenomena seperti tersebut di atas diduga sebagai akibat dari longgarnya pengawasan oleh pimpinan, selain instrument pengawasan secara konfensional hanya dipercayakan pada daftar hadir pengawai 
yang mudah dimanipulasi oleh pengawai itu sendiri. Berdasarkan uraian sebelumnya penulis tertarik untuk memilih penelitian yang berjudul "Pengaruh Pengawasan Terhadap Disiplin Kerja Pegawai Negeri Sipil pada Sekretariat DPRD Provinsi Sulawesi Tenggara.'”

\section{Metode}

Jenis penelitian yang digunakan dalam penelitian ini adalah kuantitatif Penelitian asosiatif merupakan penelitian yang bertujuan untuk mengetahui hubungan antara dua variabel atau lebih (Sugiyono, 2010: 11). Variabel dalam penelitian ini yaitu variabel pengawasan sebagai varibel $(\mathrm{X})$ dan Variabel disiplin kerja Pegawai (Y). Penelitian ini dilakukan di instansi Sekretariat DPRD Provinsi Sulawasi Tenggara, yang berada di Jl Drs Abdullah Silondae Nomor 02,Mandonga,Kota Kendari Sulawesi Tenggara 2018. Populasi merupakan keseluruhan subyek penelitian yang ada dilokasi penelitian. Sejalan dengan itu penulis melibatkan sejumlah pegawai yang ada di Sekretariat DPRD Provinsi Sulawesi Tenggara untuk dijadikan responden penelitian. Adapun yang Akan menjadi sampel dalam penelitian ini adalah seluruh pegawai di Kantor tersebut yang berjumlah 210 orang.Sampel adalah sebagian atau wakil dari populasi yang Akan diteliti (Suharsimi Arikunto, 2010: 109). Pengambilan sampel untuk penelitian menurut Suharsimi Arikunto (2010: 112), jika subjeknya kurang dari 100 orang sebaiknya diambil semuanya, jika subjeknya besar atau lebih dari 100 orang dapat diambil $10-15 \%$ atau $20-25 \%$ atau lebih. Jadi dari jumlah seluruh pegawai yan ada di Lingkup DPRD Provinsi Sulawesi Tenggara sebanyak 210 orang peneliti mengambil sampel sebanyak 53 orang $(25 \%)$ orang yang terdiri dari masing pimpinan Bidang dan bawahannya.

Analisis data menggunakan metode deskriptif kuantitatif, yaitu dengan analisis korelasiona yang menguji hubungan/pengaruh antar variabel. Adapun metode yang digunakan adalah metode deskriptif yaitu: penganalisaan yang bersifat menjelaskan atau menguraikan dari data dan informasi yang diperoleh, kemudian dikaitkan dengan teori-teori atau konsep yang relevan dalam memberikan gambaran nyata atau fakta-fakta yang sebenarnya, sehingga dapat diambil kesimpulan. 
Metode kuantitatif yaitu: metode yang digunakan untuk mengetahui hubungan/pengaruh sistem pengawasan terhadap disiplin kerja pegawai. Untuk lebih jelasnya penulis menggunakan metode regresi sederhana. Adapun bentuk persamaan regresi yang dipergunakan adalah sebagai berikut:

$$
\begin{aligned}
& \mathrm{Y}=\mathrm{b}+\mathrm{X} 1 \\
& \text { Dimana: } \\
& \mathrm{Y}=\text { Kedisiplinan kerja pegawai } \\
& \mathrm{b}=\text { Koefesien regresi } \\
& \mathrm{X}=\text { Pengawasan }
\end{aligned}
$$

\section{Hasil dan Pembahasan}

\section{Profil Umum Kantor DPRD Provinsi Sulawesi Tenggara}

\section{a. Sejarah Dewan Perwakilan Rakyat Daerah Sulawesi Tenggara}

Dewan Perwakilan Rakvat Daerah (DPRD) Provinsi Sulawesi Tenggara secara resmi terbentuk pada tanggal 27 April 1964 berdasarkan Surat Keputusan Menteri Dalam Negeri pada tanggal 23 november 1964 No. Des.2/21/26-183 telah diangkat 27 orang Anggota DPRD-GR dan dilantik oleh Bapak Eni Karim yang mewakili Menteri Dalam Negeri pada tanggal 10 januari 1965 yang sejak masa ini dimulailah pelaksanaan tugas-tugas legislatif daerah.

\section{b. Komposisi DPRD Provinsi Sulawesi Tenggara}

Dewan Perwakilan Rakyat Daerah (DPRD) Provinsi Sulawesi Tenggara sebagai salah satu unsur Pemerintah Daerah secara resmi terbentuk pada tanggai 27 April 1964 berdasarkan Surat Keputusan Menteri Dalam Negeri pada tanggal 23 november 1964 No. Des.2/21/26-1 83 telah diangkat 27 orang Anggota DPRD-GR dan dilantik oleh Menteri Dalam Negeri pada tanggal 10 januari 1965 maka sejak masa itulah pelaksanaan tugas - tugas legislatif daerah. Anggota DPRD-GR menjalankan tugasnya secara aktif hanya sampai pada pertengahan bulan oktober 1965 dan sesudah itu menjadi beku oleh karena diantara anggota-anggotanya terdapat orang-orang yang diragukan mental ideologinya terutama sehubungan dengan terjadinya tragedi nasional G.30. S/PKI. Sejak pertengahan bulan oktober 
1965 pelaksanaan tugas-tugas DPRD-GR berangsur-angsur menjadi kurang efektif dan selanjutnya selama tahun 1966 tidak dapat menjalankan tugasnya lagi. Dengan dikeluarkannya Surat Keputusan Menteri Dalam Negeri tanggal 30 januari 1967 No. Pemda 5/1/44-66 anggota - anggota DPRD-GR yang masih ada sebanyak 18 orang telah diberhentikan dengan hormat dan jabatannya dan dengan Surat Keputusan yang sama, maka diangkatlah anggota - anggota DPRD-GR yang baru sehingga DPRD-GR sudah dapat berfungsi kembali. Dalam kurun waktu satu tahun, Dewan Perwakilan Rakyat Daerah Provinsi sulawesi Tenggara mengeluarkan 20 Peraturan Daerah yang diantaranya mengenai lambang daerah provinsi Sulawesi Tenggara, pendirian perusahaan, pedoman pelaksanaan anggaran pendapatan dan belanja daerah. peraturan gaji pegawai negeri sipil, pajak, dan lainlain.

Sejak kelahiranya tahun 1964 hingga tahun 2009 DPRD Provinsi Sulawesi Tenggara telah mengalami beberapa perubahan komposisi kursi dari 30 kursi kini meningkat menjadi 45 kursi. Perubahan tampak pula pada partai peraih kursi terbanyak dari periode orde lama, orde baru hingga reformasi. Pada periode orde lama Partindo merupakan partai yang mendudukan kursi terbanyak di DPRD Sulawesi Tenggara. Selanjutnya pada tahun 1967-2009 partai Golkar memposisikan diri sebagai partai penguasa (the rulling party). Dominasi Golkar di Sulawesi Tenggara mengalami keruntuhan pada Pemilu 2014, dimana PAN sebagai partai yang lahir di era reformasi berhasil memenangkan Pemilu legislatif 2014. Eksistensi PAN di Sulawesi Tenggara sangat menonjol setelah Nur Alam sebagai Ketua PAN terpilih menjadi Gubernur Sulawesi Tenggara. Melalui posisi tersebut, benar-benar dimanfaatkan oleh PAN sebagai media konsolidasi kekuatan PAN.

\section{Visi Dan Misi Kantor DPRD Provinsi Sulawesi Tenggara}

Visi merupakan rumusan umum mengenai keadaan yang di inginkan pada akhir Periode perencanaan, visi sekteriat DPRD provinsi sulawesi tenggara adalah terwujudnya pelayanan sekretariat dewan yang profesional, transparan dan akuntabel dalam memfasilitasi pelaksanaan tugas DPRD provinsi sulawesi tenggara. Visi sekretariat DPRD provinsi sulawesi tenggara mempunyai makna 
sebagai berikut: Pertama, Terwujudnya pelayanan sekretariat DPRD yang profesional sesuai dengan tugas pokok dan fungsi yang di emban, mencerminkan totalitas kerja dan pelayanan berkualitas yang di berikan sejalan dengan tumbuh dan kembangnya keahlian SDM dalam jajaran sekretariat DPRD provinsi sulawesi tenggara dalam pelaksanaan tugas dan fungsinya. Adapub misi adalah rumusan mengenai upaya-upaya yang akan di laksanakan untuk mewujudkan visi, dalam mewujudkan visi tersebut di perlukan tindakan nyata yang sesuai dengan peran strategis dari Sekretariat DPRD Provinsi Sulawesi Tenggara yaitu :

1. Meningkatkan kualitas SDM Sekretariat DPRD Provinsi Sulawesi Tenggara

2. Meningkatkan disiplin

3. Meningkatkan sistem informasi yang terbuka

4. Menyempurnakan Standar Oprasional Pelayanan

5. Melaksanakan pelayanan prima

\section{Deskripsi Variabel Pengawasan}

Variabel pengawasan dalam penelitian ini diukur berdasarkan tiga indikator. Rekapitulasi jawaban responden atas pernyataan responden diuraikan sebagai berikut:

Tabel 1. Tanggapan Responden Mengenai Pengawasan

\begin{tabular}{|c|c|c|c|c|c|c|c|c|c|c|c|c|c|}
\hline \multirow{3}{*}{ Indikator } & \multirow{3}{*}{ Item } & \multicolumn{10}{|c|}{ Jawaban Responden (Skor) } & \multirow{3}{*}{$\begin{array}{c}\text { Total } \\
\text { Sampel } \\
\text { (F) }\end{array}$} & \multirow{3}{*}{$\begin{array}{l}\text { Total } \\
\text { Rerata }\end{array}$} \\
\hline & & \multicolumn{2}{|c|}{ SS (5) } & \multicolumn{2}{|c|}{$S(4)$} & \multicolumn{2}{|c|}{$N(3)$} & \multicolumn{2}{|c|}{ TS (2) } & \multicolumn{2}{|c|}{ STS (1) } & & \\
\hline & & $\mathbf{F}$ & $\%$ & $\mathbf{F}$ & $\%$ & $\mathbf{F}$ & $\%$ & $\mathbf{F}$ & $\%$ & $\mathbf{F}$ & $\%$ & & \\
\hline \multirow{3}{*}{$\begin{array}{c}\text { Pengawasan } \\
\text { Langsung }\end{array}$} & $\mathrm{x} 1.1$ & 11 & 20,75 & 31 & 58,49 & 11 & 20,75 & 0,00 & 0,00 & 0,00 & 0,00 & 53 & 4,00 \\
\hline & $\mathrm{X} 1.2$ & 4 & 7,55 & 26 & 49,06 & 23 & 43,40 & 0,00 & 0,00 & 0,00 & 0,00 & 53 & 3,64 \\
\hline & \multicolumn{12}{|c|}{ Rata-rata Indikator } & 3,82 \\
\hline \multirow{3}{*}{$\begin{array}{c}\text { Pengawasan } \\
\text { Tidak } \\
\text { Langsung }\end{array}$} & $\mathrm{X} 1.3$ & 9 & 16,98 & 33 & 62,26 & 11 & 20,75 & 0,00 & 0,00 & 0,00 & 0,00 & 53 & 3,96 \\
\hline & $\mathrm{X} 1.4$ & 3 & 5,66 & 24 & 45,28 & 26 & 49,06 & 0,00 & 0,00 & 0,00 & 0,00 & 53 & 3,57 \\
\hline & \multicolumn{12}{|c|}{ Rata-rata Indikator } & 3,76 \\
\hline \multirow{4}{*}{$\begin{array}{c}\text { Pengawasan } \\
\text { Melekat }\end{array}$} & $\mathrm{X} 1.5$ & 5 & 9,43 & 17 & 32,08 & 27 & 50,94 & 4 & 7,55 & 0,00 & 0,00 & 53 & 3,43 \\
\hline & $\mathrm{X} 1.6$ & 4 & 7,55 & 31 & 58,49 & 18 & 33,96 & 0,00 & 0,00 & 0,00 & 0,00 & 53 & 3,74 \\
\hline & \multicolumn{12}{|c|}{ Rata-rata Indikator } & 3,58 \\
\hline & \multicolumn{12}{|c|}{ Rata-Rata Variabel } & 3,72 \\
\hline
\end{tabular}

Sumber: data primer diolah, 2018

Dalam hal ini khususnya untuk variabel pengawasan pada indikator pengawasan langsung untuk item X1.1 menunjukkan bahwa responden atau 
pegawai negeri sipil kantor DPRD Provinsi Sulawesi Tenggara bahwasanya pimpinan selalu mengadakan inspeksi mendadak disaat jam kerja berlangsung. Hal ini berupaya untuk melihat secara langsung bagaimana tindakan pegawai berlangsungnya kegiatan jam kerja, guna mengantisipasi adanya oknum pegawai yang tidak melaksanakan kewajiban pada saat jam kerja sedang berlangsung. Pernyataan ini didukung oleh hasil dari olahan data yang diambil dari jawaban responden mengenai pengawasan pada item X1.1 yang mempunyai total nilai item sebesar 4,00 dan termasuk dalam kategori tinggi atau baik.

Pada item X1.2 menunjukkan bahwa para pimpinan atau dalam artian pengawas, melakukan pengecekan pada absensi harian pegawai negeri sipil kantor DPRD Provinsi Sulawesi Tenggara secara runtin guna meningkatkan kedisiplinan kerja para pegawai negeri sipil. Hal ini dibuktikan oleh hasil rekapitulasi data berdasarkan jawaban dari para responden mengenai pengawasan secara langsung yang memiliki total niali item sebesar 3,64 dan termasuk dalam kategori tinggi atau baik.

Berdasarkan hasil persepsi responden atas indikator pengawasan langsung dengan 2 indikator, yang dimana secara rutin pimpinan melakukan inspeksi mendadak dan melakukan pengecekan absensi para pegawai negeri sipil kantor DPRD Provinsi Sulawesi Tenggara. Pengawasan langsung ini bukan semata-mata untuk menekan pegawai dalam melakukan pekerjaan, namun tujuan yang sebenarnya diadakaan pengawasaan langsung adalah membentuk dan membangun karakter jiwa kedisiplinan kerja para pegawai itu sendiri. Bila mana telah tercapai yang dinamakan displin kerja melalui adanya pengawasan langsung ini maka efesiensi dan efektifitas meningkat. Hal ini dapat dibuktikan melalui perhitungan rata-rata indikator pada pengawasan langsung yang meliki nilai sebesar 3,82 dan dapat dikategorikan tinggi atau baik.

Pada item X1.3 dimana pimpinan telah melaksanakan permintaan laporan dalm pelaksanaan tugas sehari-hari dari para pegawai negeri sipil kantor DPRD Provinsi Sulawesi Tenggara dengan baik. Hal ini dibuktikan dari hasil total jawaban responden sebesar 3,96 yang dapat dikategorikan tinggi atau baik. 
Pada item X1.4 pimpinan telah mengadakan evaluasi terhadap tugas dan pekerjaan dari para pegawai negeri sipil kantor DPRD Provinsi Sulawesi Tenggara secara berkala. Hal ini dibuktikan pada hasil rekapitulasi data berdasarkan jawan oleh para responden dengan total nilai sebesar 3,57 dengan kategori tinggi atau baik.

Berdasarkan dari hasil perhitungan rata-rata dari indikator pengawasan tidak langsung menunjukkan nilai 3,76 yang termasuk dalam kategori tinggi atau baik. Oleh karenanya pimpinan dalam mengevaluasi hasil dari laporan pelaksanaan tugas dan pekerjaan dapat menghasil kedisiplinan kerja dari para pegawai negeri sipil kantor DPRD Provinsi Sulawesi Tenggara. Dari pengawasan tidak langsung ini juga berguna untuk pengambilan suatu keputusan oleh para pimpinan yang dibawahinya dalam melakukan tugas dan pekerjaan kedepannya.

Pada item X1.5 para kepala atau pimpinan bagian kantor DPRD Provinsi Sulawesi Tenggara melakukan pengawasan terlebih dulu sebelum perkerjaan berlangsung, hal ini dibuktikan dari hasil total jawaban responden mengenai hal ini sebesar 3,43 cukup tinggi atau cukup baik.

Pada item X1.6 para pimpinan juga melakukan pengawan setelah tugas dan pekerjaan telah berlangsung guna memastikan tugas dan pekerjaan dari para pegawai negeri sipil telah terlaksana dengan semestinya. Hal ini dibuktikan pada hasil perhitungan rekapitulasi data dengan total 3,74 terkategori tinggi atau baik.

Berdasarkan indikator pengawasan melekat atau pengawasan pendahuluan menyatakan bahwa pimpinan bersifat antisipasi dalam melakukan pengawasan tugas dan pekerjaan dari para pegawai negeri sipil sebelum dan sesudah melakukan tugas dan pekerjaan masing-masing. Dari sifat yang antisipasi yang dilakukan oleh para pimpinan berguna untuk mendisiplikan para pegawai negeri sipil dalam melakukan tugas dan pekerjaan mereka. Hal ini dibuktikan pada nilai rata-rata variabel dari hasil rekapitulasi data sebesar 3,58 atau dapat dikategorikan tinggi atau baik.

Pada variabel pengawasan ini, pimpinan berperan besar dalam melakukan pengawasan langsung, pengawasan tidak langsung maupun pengawasan melekat atau pengawasan pendahuluan. Pengawasan yang dilakukan oleh pimpinan ini bukan berarti pegawai negeri sipil kantor DPRD Provinsi Sulawesi Tenggara harus 
terus diawasi oleh pimpinannya, melainkan guna membentuk kedisiplinan dalam bekerja setiap individu maupun secara tim. Dengan pengawasan yang dilakukan secara rutin ini dapat membentuk karakter kerja pegawai yang disiplin akan suatu hal tertentu. Hal ini dibuktikan pada hasil rekapitulasi data berdasarkan dari jawaban responden sebesar 3.72 dan termasuk kategoti tinggi atau baik.

\section{Deskripsi Variabel Displin Kerja}

Variabel disiplin kerja dalam penelitian ini diukur berdasarkan 3 indikator. Rekapitulasi jawaban responden atas pernyataan responden diuraikan sebagai berikut:

Tabel 2. Tanggapan Responden Mengenai Disiplin Kerja

\begin{tabular}{|c|c|c|c|c|c|c|c|c|c|c|c|c|c|}
\hline \multirow{3}{*}{ Indikator } & \multirow{3}{*}{ Item } & \multicolumn{10}{|c|}{ Jawaban Responden (Skor) } & \multirow{3}{*}{$\begin{array}{c}\text { Total } \\
\text { Sampel } \\
(\mathbf{F})\end{array}$} & \multirow{3}{*}{$\begin{array}{l}\text { Total } \\
\text { Rerata }\end{array}$} \\
\hline & & \multicolumn{2}{|c|}{ SS (5) } & \multicolumn{2}{|c|}{ S (4) } & \multicolumn{2}{|c|}{$\mathbf{N}(3)$} & \multicolumn{2}{|c|}{ TS (2) } & \multicolumn{2}{|c|}{ STS (1) } & & \\
\hline & & $\mathbf{F}$ & $\%$ & $\mathbf{F}$ & $\%$ & $\mathbf{F}$ & $\%$ & $\mathbf{F}$ & $\%$ & $\mathbf{F}$ & $\%$ & & \\
\hline \multirow{3}{*}{ Tepat Waktu } & Y1 & 24 & 45,28 & 29 & 54,72 & 0 & 0,00 & 0 & 0,00 & 0 & 0,00 & 53 & 4,45 \\
\hline & $\mathbf{Y} 2$ & 26 & 49,06 & 27 & 50,94 & 0 & 0,00 & 0 & 0,00 & 0 & 0,00 & 53 & 4,49 \\
\hline & \multicolumn{12}{|c|}{ Rata-rata Indikator } & $\mathbf{4 , 4 7}$ \\
\hline \multirow{3}{*}{$\begin{array}{c}\text { Menggunakan } \\
\text { Peralatan } \\
\text { kantor } \\
\text { dengan baik }\end{array}$} & Y3 & 23 & 43,40 & 30 & 56,60 & 0 & 0,00 & 0 & 0,00 & 0 & 0,00 & 53 & $\mathbf{4 , 4 3}$ \\
\hline & Y4 & 27 & 50,94 & 25 & 47,17 & 1 & 1,89 & 0 & 0,00 & 0 & 0,00 & 53 & 4,49 \\
\hline & \multicolumn{12}{|c|}{ Rata-rata Indikator } & 4,46 \\
\hline \multirow{4}{*}{$\begin{array}{c}\text { Taat } \\
\text { Terhadap } \\
\text { Aturan } \\
\text { Kantor } \\
\end{array}$} & Y5 & 31 & 58,49 & 22 & 41,51 & 0 & 0,00 & 0 & 0,00 & 0 & 0,00 & 53 & 4,58 \\
\hline & Y6 & 23 & 43,40 & 25 & 47,17 & 5 & 9,43 & 0 & 0,00 & 0 & 0,00 & 53 & 4,34 \\
\hline & \multicolumn{12}{|c|}{ Rata-rata Indikator } & 4,46 \\
\hline & \multicolumn{12}{|c|}{ Rata-Rata Variabel } & $\mathbf{4 , 4 7}$ \\
\hline
\end{tabular}

Sumber: data primer diolah, 2018

Tabel 2 diatas menunjukkan bahwa rata-rata variabel disiplin kerja dikategorikan baik dengan nilai rata-rata sebesar 4,47, hal ini menunjukkan bahwa disiplin kerja mempengaruhi efektivitas kerja pegawai negeri sipil kantor DPRD Provinsi Sulawesi Tenggara mengenai tentang disiplin akan waktu, disiplin dalam menggunakan peralatan kantor dan disiplin terhadap aturan kantor.

Variabel disiplin kerja mempunyai 3 indikator yaitu tepat waktu, menggunakan peralatan kantor dengan baik dan taat terhaap aturan kantor . Diantara ke-3 indikator tersebut, yang mempunyai hasil skor rata-rata tertinggi adalah tepat waktu. Bisa ditarik kesimpulan bahwa pegawai negeri sipil pada kantor DPRD Provinsi Sulawesi Tenggara memiliki kedisiplinan terhadap waktu yang dimana ketepatan waktu dapat menandakan individu tersebut mempunyai 
kedisiplinan yang tinggi. Ketepatan waktu yang dicapai oleh para pegawai dikarenakan pengawasan yang dilakukan oleh pimpinan telah berjalan sesuai dengan apa yang diharapkan.

Hal ini tidak semata-mata memberikan penilaian bahwa indikator selain tepat waktu kurang memadai walaupun hasil rata-rata skor pernyataan semua mencakup, namun ada baiknya untuk lebih meningkatkan lagi menjadi lebih baik guna menambah nilai kedisplinan kerja pada pegawai negeri sipil kantor DPRD Provinsi Sulawesi Tenggara.

\section{Kesimpulan}

Berdasarkan hasil penelitian, maka kesimpulan dalam penelitian ini adalah pengawasan berpengaruh positif dan tidak signifikan terhadap disiplin kerja, semakin baik pengawasan yang dilakukan oleh pimpinan maka disiplin kerja para pegawai negeri sipil akan semakin meningkat.

Pegawai Negeri Sipil pada Sekertariat DPRD Provinsi Sulawesi Tenggara mempunyai pimpinan yang secara rutin mengadakan inspeksi pada saat jam kerja berlangsung, meminta laporan dalam pelaksanaan tugas, dan mengadakan evaluasi terhadap tugas yang diemban setiap pegawainya. Melakukan pengawasan terlebih dahulu dan sesudah pekerjaan berlangsung rutin dilakukan oleh pimpinan Pegawai negeri Sipil Pada Sekertariat DPRD Provinsi Sulawesi Tenggara. Hal ini menyebabkan pegawai pada Sekertariat DPRDP Provinsi Sulawesi Tenggara disipilin dan taat terhadap prosedur atau aturan-aturan yang ada pada kantor Pegawai Negeri Sipil Sekertariat DPRD Provinsi Sulawesi Tenggara.

Oleh karena itu, pengawasan tentunnya sangat penting dalam mendisiplikan para pegwai negeri sipil yang berdinas di sekretariat DPRD Privinsi Sulawesi Tenggara, dan tentunya peran dari para pengawas yang sebagai instrument dalam menjalan pengawasan supaya aktifitas dari para pegawai negeri sipil sekretariat DPRD Provinsi Sulawesi Tenggara berjalan sesuai dengan yang diharapkan sebelumnya. 


\section{Referensi}

Arikunto, Suharsimi. (2010). Prosedur Penelitian Suatu Pendekatan Praktik. Jakarta: Rineka Cipta

Ahadiningsih, Restu.(2008) Pengaruh Pengawasan Terhadap Disiplin Kerja Pegawai Negeri Sipil Pada Kantor Sekretariat pada Kabupaten Serdang Bedagai, Skripsi mahasiswi Fakultas Ilmu Sosial dan Ilmu Politik, Jurusan Administrasi Negara, Universitas Sumatra Utara.

Ahmad Tohardi. (2002). Pemahaman Praktis Manajemen Sumber Daya Manusia, Universitas Tanjung Pura, Mandar Maju, Bandung

Asmiarasih Tety. (2006). Pengaruh Pengawasan Terhadap Disiplin Kerja Pegawai Kantor Badan Kepegawaian Daerah Brebes Fakultas Ilmu Social Universitas Semarang

Bacal,Robert (2005).Performance Management,Edisi Bahasa Indonesia Jilid 3, PT.SUN, Jakarta.

Fattah, Nanang. (2004). Konsep Manajemen Berbasis Sekolah (MBS) dan Dewan Sekolah. Bandung: Pustaka Bani Quraisy.

Ghozali, Imam. (2006). Aplikasi Analisis Multivariate dengan Program SPSS.

(Edisi Ke 4). Semarang: Badan Penerbit Universitas Diponegoro

Hani Handoko. (2010).Manajement Personalia Dan Sumber Daya Manusia,Edisi Kedua, BPFE UGM Yogyakarta.

Komaruddin. (2001). Ensiklopedia Manajemen, Edisi ke-5, Jakarta: Bmi Aksara.

Makmur. (2009). Teori Manajemen Stratejik Dalam Pemerintahan dan Pembangunan. Refika Aditama, Bandung.

Manullang, M. (2006). Dasar-dasar Manajemen. Gajahmada University press. Jakarta.

Martoyo, Susilo. (2000). Manajemen Sumber Daya Manusia. BPFE-UGM. Yogyakarta.

Mathis Robert L dan Jackson John H.(2002).Human Resource Management, Ali Bahasa. Jakarta: Salemba Empat.

Moekijat.(2009).Manajement Personalia Dan Sumber Daya Manusia Mandar Maju, Jakarta. 
Moenir.(2002).Manajement Pelayanan Umum Di Indonesia.Jakarta:PT Bumi Aksara.

Siagian, Sondang P. (2002). Kiat Meningkatkan Produktivitas Kerja. Rineka Cipta. Jakarta.

Siagian, Sondang P. (2008). Filsafat Administrasi Edisi Revisi. Bumi Aksara, Jakarta.

Singodimedjo \& Sutrisno.(2012). Menajemen Sumber Daya Manusia. Jakarta: Bumi Aksara/Kencana

Sugiyono, 2010. Metode Penelitian Administrasi dilengkapi dengan Metode R\&D. Alfabeta, Bandung.

Sugiyono. (2010). Metode Penelitian Kuantitatif dan RND. Bandung: Alfabeta. Sujamto. (2014). Pengertian Pengawasan,Jakarta:ghalia indah. Undang-Undang Nomor 5 tahun 2014 tentang Aparatur Sipil Negara.

Winardi. (2007). Manajemen Perilaku Organisasi, Edisi Revisi, Jakarta, Kencana Prenada Media Group. 